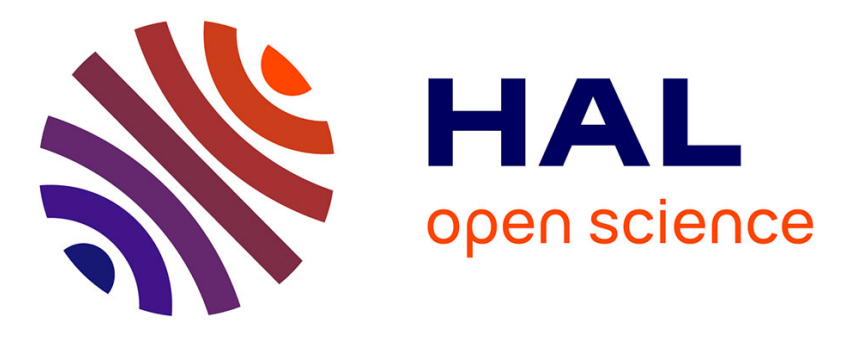

\title{
Simplified numerical approach for incremental sheet metal forming process
}

Lanouar Ben Ayed, Camille Robert, Arnaud Delamézière, Mohammed Nouari, Jean-Louis Batoz

\section{- To cite this version:}

Lanouar Ben Ayed, Camille Robert, Arnaud Delamézière, Mohammed Nouari, Jean-Louis Batoz. Simplified numerical approach for incremental sheet metal forming process. Engineering Structures, 2014, 62-63, pp.75-86. 10.1016/j.engstruct.2014.01.033 . hal-01067055

\section{HAL Id: hal-01067055 https://hal.science/hal-01067055}

Submitted on 22 Sep 2014

HAL is a multi-disciplinary open access archive for the deposit and dissemination of scientific research documents, whether they are published or not. The documents may come from teaching and research institutions in France or abroad, or from public or private research centers.
L'archive ouverte pluridisciplinaire HAL, est destinée au dépôt et à la diffusion de documents scientifiques de niveau recherche, publiés ou non, émanant des établissements d'enseignement et de recherche français ou étrangers, des laboratoires publics ou privés. 


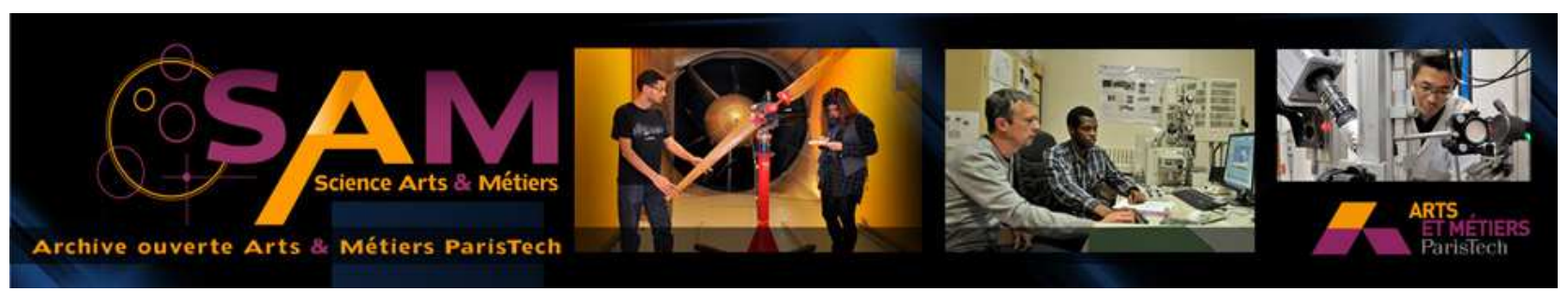

\section{Science Arts \& Métiers (SAM)}

is an open access repository that collects the work of Arts et Métiers ParisTech researchers and makes it freely available over the web where possible.

This is an author-deposited version published in: http://sam.ensam.eu

Handle ID: .http://hdl.handle.net/10985/8600

\section{To cite this version :}

Lanouar BEN AYED, Camille ROBERT, Arnaud DELAMÉZIÈRE, Mohammed NOUARI, JeanLouis BATOZ - Simplified numerical approach for incremental sheet metal forming process Engineering Structures - Vol. 62-63, p.75-86 - 2014 


\title{
Simplified numerical approach for incremental sheet metal forming process
}

\author{
L. Ben Ayed ${ }^{\mathrm{a}, *}$, C. Robert $^{\mathrm{b}}$, A. Delamézière ${ }^{\mathrm{a}}$, M. Nouari ${ }^{\mathrm{a}}$, J.L. Batoz ${ }^{\mathrm{c}}$ \\ a Laboratoire d'Energétique et de Mécanique Théorique et Appliquée, LEMTA CNRS-UMR 7563, Ecole des Mines d'Albi, Université de Lorraine, GIP-InSIC, 27 rue d'Hellieule, \\ 88100 Saint-Dié-des-Vosges, France \\ ${ }^{\mathrm{b}}$ Arts et Métiers ParisTech - Laboratoire LPMI, 2 boulevard du Ronceray, BP 93525, 49035 Angers Cedex 1, France \\ ${ }^{\mathrm{c}}$ Université de Technologie de Compiègne (UTC) - Laboratoire Avenues-GSU, BP 60319, 60203 Compiègne Cedex, France
}

Keywords:

Incremental sheet forming

Simplified analysis modelling

Shell element DKT12

\begin{abstract}
A B S T R A C T
The current work presents a finite element approach for numerical simulation of the incremental sheet metal forming (ISF) process, called here "ISF-SAM" (for ISF-Simplified Analysis Modelling). The main goal of the study is to develop a simplified FE model sufficiently accurate to simulate the ISF process and quite efficient in terms of CPU time. Some assumptions have been adopted regarding the constitutive strains/ stresses equations and the tool/sheet contact conditions. A simplified contact procedure was proposed to predict nodes in contact with the tool and to estimate their imposed displacements. A Discrete Kirchhoff Triangle shell element called DKT12, taking into account membrane and bending effects, has been used to mesh the sheet. An elasto-plastic constitutive model with isotropic hardening behaviour and a static scheme have been adopted to solve the nonlinear equilibrium equations. Satisfactory results have been obtained on two applications and a good correlation has been shown compared to experimental and numerical results, and at the same time a reduction of CPU time more than $60 \%$ has been observed. The bending phenomenon studied through the second application and the obtained results show the reliability of the DKT12 element.
\end{abstract}

\section{Introduction}

Conventional sheet metal forming processes such as stamping and hydro-forming are realized with dies. The basic requirement is that the production volume is large, but the tools cost is very high. The recent market requirements tend to vary quickly and the conventional sheet forming processes with dies become less competitive for low volume production. Consequently, new flexible manufacture methods have to be developed. To achieve the changing requirements of the market, the ISF process has been suggested as a fabrication process with good potentialities. In addition, several adaptations for this process are introduced and explored, including the use of one or two dies, a mobile support, a rotating tool, and the use of water jet instead of the forming tool [1]. In the concept illustrated in Fig. 1a, the process is nowadays referred to as SPIF (Single Point Incremental Forming): a flat blank is clamped around its edges and is deformed progressively by a simple hemispherical tool which moves according to a known path. Another variant of this process (Fig. 1b), called nowadays Two Points Incremental Forming (TPIF) in which the flat blank is

\footnotetext{
* Corresponding author. Tel.: +33 329421821; fax: +33 329421825

E-mail address: lanouar.ben-ayed@univ-lorraine.fr (L. Ben Ayed).
}

deformed by two contact points. According to the historical review made by Emmens et al. [2] about the ISF technological developments through the years and the state of the art given by Jeswiet et al. [3], the TPIF is older than SPIF and both process are two common types of Asymmetric Incremental Sheet Forming (AISF).

Today, the ISF process is well suitable and highly recommended for small volume and varied productions, and also is considered as a rapid prototyping technique. The principal goal which motivates the development of ISF is the flexibility of that process as it has been shown by Ambrogio et al. [4] for medical products manufacturing. In fact, different components can be made without the need to manufacture new tooling: the tool path defines the geometry of parts, so a new tool path can be planned and used without incurring additional costs of tool development. Generally in ISF, the most commonly used materials are aluminium and steel alloys, although investigations performed by Jackson et al. [1] have been shown that the ISF process can be successfully applied to form sandwich panels composed of propylene with mild steel and aluminium metallic foams. Furthermore, that process has an important aspect concerning the formability: It gives higher forming limits compared to conventional sheet metal forming processes [5]. A simplified process was proposed by Allwood et al. [6] to gain insight into this phenomenon for a broad class of incremental 


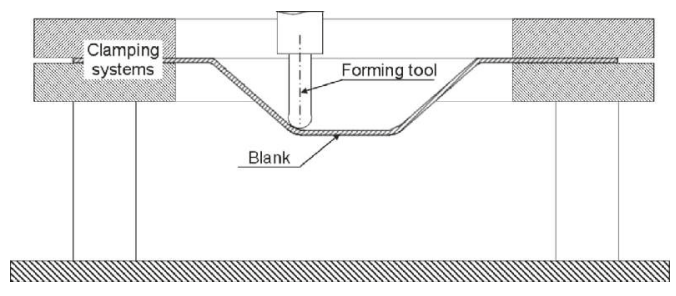

(a)

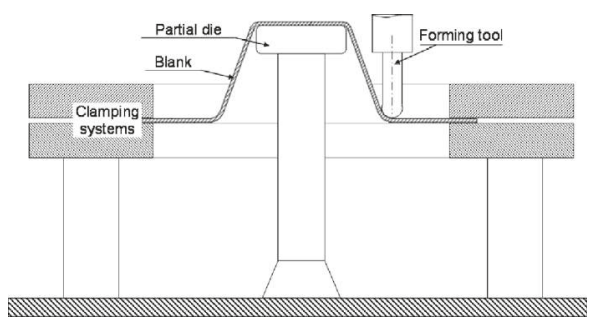

(b)

Fig. 1. Process variants: SPIF (a) and TPIF (b).

forming processes. They claimed that the forming limit is increased when through thickness shear is present. It was observed that in a plane perpendicular to the tool path the deformation of the sheet is mainly by stretching and bending. In a plane parallel to the tool path, significant through thickness shear was observed. To study and give explanation concerning the higher forming limits for ISF process, solid finite elements are used by Eyckens et al. [7] but the simulation time was found extremely high. On the other hand, this process suffers of two major drawbacks which limits its industrial application and requires additional studies:

- the geometrical accuracy is one of the most relevant point of weakness, although many investigations have been focused on this topic. Guzmán et al. [8] studied a two-slope SPIF pyramid with two different depths and they concluded that the shape deviations is linked mainly to the elastic strains due to structural elastic bending, plus a minor contribution of localized springback. Micari et al. [9] presented different strategies to reduce geometrical error, taking into account the influence of the most relevant parameters, and concluded that the optimization of the tool path is the most promising solution. The investigations, carried out by Azaouzi and Lebaal [10], and Rauch et al. [11], confirm that a tool path optimization leads to an improvement of the geometrical accuracy;

- the production rate is not very high compared to other sheet metal forming processes, due to the characteristic of point-topoint forming process. In fact, the sheet is deformed locally by the tool which moves progressively on a very long trajectory in order to form complex shapes.

Several researchers have focused their attention on modelling and numerical simulation of the ISF process. Finite element analyses, using an explicit method, have been performed by Hirt et al. [12] to investigate two major limits of the ISF: the limitation on the maximum achievable wall angle and the occurrence of geometric deviations. These drawbacks have been investigated and two methods are proposed to enlarge the range of process applications: a multi-stage forming strategy to produce steep flanges of up to 81 ", and a correction algorithm to enhance the geometric accuracy. In addition, a Gurson-Tveergard-Needleman damage law has been applied to investigate the effect of process parameters such as the tool size and the vertical pitch on the fracture risk. Through a number of case studies Duflou et al. [13] have demonstrated that the use of multi-stage strategies allows to form geometries exceeding conventional single-stage forming limits. From these case studies it was concluded that there is no reason to consider 90" wall angles as the ultimate process limit. In addition, the thinning of the sheet during multi-stage forming can exceed the maximum reduction of the thickness observed in single-stage processing. Bambach et al. [14] have shown, through benchmark parts, that the multi-stage forming gives an increased accuracy compared to the single-stage forming and that the multi-stage forming strategies could be considered as an alternative to the overbending strategies.
Despite the progress achieved, modelling the ISF process continues to be a challenging task. An implicit scheme could lead to a high CPU time compared to an explicit one, mainly due to the point-to-point alternating contact conditions [15]. With explicit schemes, thanks to mass-scaling technique, it is possible to significantly reduce the computational time. However, it is not trivial to find the right mass-scaling factor according to [16]. Despite their high CPU time, implicit schemes are unconditionally stable and will always give a better solution compared to explicit schemes.

In summary, the literature shows that several research investigations performed numerical modelling of the process based on static or dynamic, implicit or explicit approaches, using membrane, shell or solid elements and considering classical or micro-macro models. Most of these models can be very precise, but lead to very high computational times and need expensive computer resources. It is incontestable that some numerical methods may not be desirable for complex applications if they involve very significant computational times. In order to overcome that problem, techniques such as adaptive remeshing [17], and substructuring approach [18] have been proposed for implicit simulations. A simplified model for ISF based on a purely geometrical approach to the kinematics of material points has been developed [19] and a more accurate calculation of the sheet thickness was shown compared to the sine law. However, it seems necessary to enhance the proposed model because it is based only on membrane deformation, but without taking into account the mechanical equilibrium, the material behaviour, and the bending effects.

The present investigation is a continuation of work that started using an incremental deformation theory [20,21]. Satisfactory results are obtained during the European project FLEXFORM [22] and shown by Yu et al. [23]. The main goal is focused on the development of a simplified numerical approach to simulate the ISF with precision and with reduction of CPU time in mind. Firstly, the kinematics and the elasto-plastic constitutive model constitutive law are presented. Then, the discretized equations governing equilibrium states of the structure and the formulation aspects of the shell element DKT12 including the bending effects, are briefly presented. Finally, a simplified procedure to manage the contact between the tool and the sheet is developed. The results obtained for a pyramidal shape benchmark test are compared to experimental results. Other numerical results carried out using the commercial finite element code Abaqus confirm the validity of the proposed simplified approach. The bending phenomenon is investigated through a square box test that confirms the potentiality of the present FEM.

\section{Kinematic of the DKT12 element and constitutive law}

In this section kinematic aspects concerning the DKT12 element will be briefly summarized. The shell element called DKT12 (Discrete Kirchhoff Triangle), which is implanted in our FE model was previously developed by Batoz et al. [24,25]. A Kirchhoff assumption has been considered to define the position vectors of 
material points at the initial flat blank $C^{\circ}$ and the $k$ th 3D configuration $\mathrm{C}^{\mathrm{k}}$ of the workpiece (Fig. 2).

The deformation gradient tensors at points $q_{0}$ and $q$ with respect to $p$ are defined in the local coordinate system by:

$d x_{q_{0}}=\left[F_{0}\right]^{-1} d x$ and $d x_{q}=\left[F_{z}\right] d x$

Then, the inverse of the Cauchy-Green left tensor between $q$ and $q_{0}$ is defined as:

$[B]^{-1}=[F]^{-T}[F]^{-1}$

where $[F]^{-1}$ is the inverse deformation gradient tensor, which is obtained from Eq. (1):

$[F]^{-1}=\left[F_{0}\right]^{-1}\left[F_{z}\right]^{-1}$

with:

$$
\begin{aligned}
& {\left[F_{0}\right]^{-1}=\left[\overrightarrow{x_{p, x}}-\overrightarrow{u_{p, x}} \quad: \quad \overrightarrow{x_{p . y}}-\overrightarrow{u_{p, y}} \quad: \quad \frac{1}{\lambda_{3}} \overrightarrow{n_{0}}\right]} \\
& {\left[F_{z}\right]=\left[\overrightarrow{x_{p, x}}+z \overrightarrow{n_{, x}} \quad \vdots \quad \overrightarrow{x_{p, y}}+z \overrightarrow{n_{y}} \quad \vdots \quad \vec{n}\right]}
\end{aligned}
$$

$\left[F_{0}\right]^{-1}$ and $\left[F_{z}\right]^{-1}$ are the membrane and bending deformation gradient tensors, respectively, $\lambda_{3}=z / z_{0}=h / h_{0}$ is the thickness stretch.

The thickness stretch is assumed to be fixed through the thickness. So, the tensor $[B]^{-1}$ takes the following simple form:

$$
[B]^{-1}=\left[\begin{array}{ccc}
a & b & 0 \\
b & c & 0 \\
0 & 0 & \lambda_{3}^{-2}
\end{array}\right]
$$

The eigenvalue calculation of $[B]^{-1}$ gives two principal plane stretches $\lambda_{1}, \lambda_{2}$ and their direction transformation matrix $[M]$. Then, the thickness stretch $\lambda_{3}$ is calculated by the assumption of constant volume. Finally, the logarithmic strains are obtained as:

$[\varepsilon]=[M][\ln \lambda][M]^{T}$

In the current work, the yield stress function is written using the Hill criterion and considering a plane stress condition for a planar isotropic sheet:

$F\left(\{\sigma\}, \bar{\varepsilon}^{p}\right)=\bar{\sigma}-\sigma_{y}\left(\bar{\varepsilon}^{p}\right)$

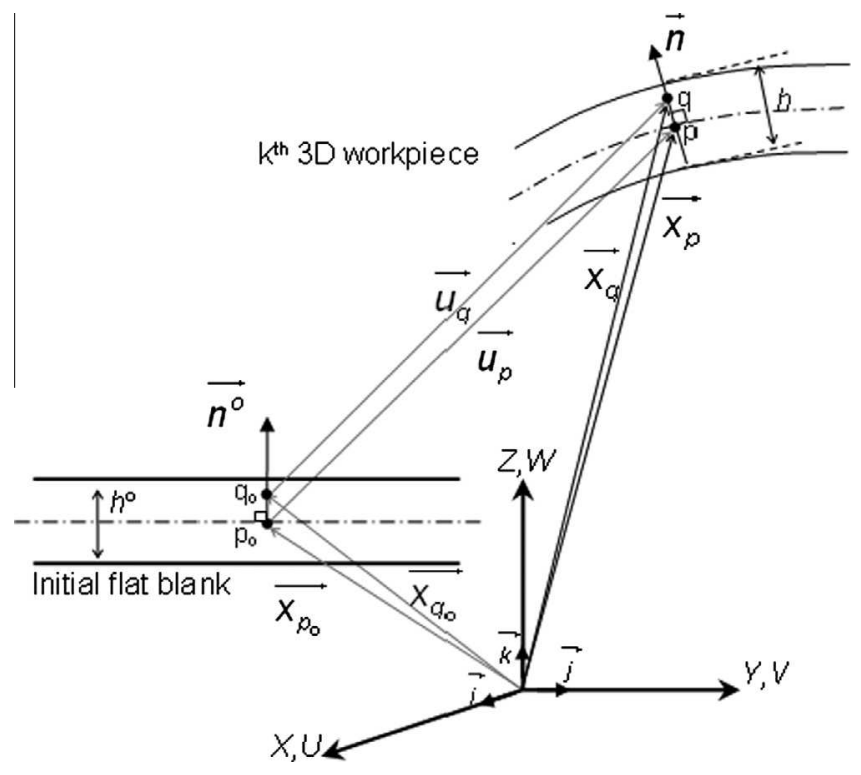

Fig. 2. Kinematics of a thin shell in sheet forming. where $\sigma_{y}$ is the yield stress which is in function of the effective plastic strain $\bar{\varepsilon}^{p}$, and $\bar{\sigma}$ is the effective stress:

$\bar{\sigma}=(\langle\sigma\rangle[P]\{\sigma\})^{1 / 2}$

with $\langle\sigma\rangle=\left\langle\begin{array}{lll}\sigma_{x} & \sigma_{y} & \sigma_{x y}\end{array}\right.$ and the matrix [P] is in function of the mean planar isotropic coefficient $\bar{r}$ :

$[P]=\left[\begin{array}{ccc}1 & -\frac{\bar{r}}{1+\bar{r}} & 0 \\ -\frac{\bar{r}}{1+\bar{r}} & 1 & 0 \\ 0 & 0 & \frac{2(1+2 \bar{r})}{1+\bar{r}}\end{array}\right], \quad \bar{r}=\frac{r_{0}+2 r_{45}+r_{90}}{4}$

where $r_{0}, r_{45}$ and $r_{90}$ are the Lankford coefficients.

At each iteration, and for each integration point, a discrete strain increment $\{\Delta \varepsilon\}$ is computed and additively decomposed into elastic and inelastic parts:

$\{\Delta \varepsilon\}=\left\{\Delta \varepsilon^{e}\right\}+\left\{\Delta \varepsilon^{p}\right\}$

Then the increment of stress $\{\Delta \sigma\}$ will be evaluated and the stress vector is updated:

$\left\{\sigma_{n+1}\right\}=\left\{\sigma_{n}\right\}+\{\Delta \sigma\}$

The increment of stress is given by the generalized Hooke's law as:

$\{\Delta \sigma\}=[C]\left\{\Delta \varepsilon^{e}\right\}$

where $[C]$ is the elastic stiffness matrix.

When the material deforms elastically, the elastic strain part is equal to the total strain increment $\left(\{\Delta \varepsilon\}=\left\{\Delta \varepsilon^{e}\right\}\right)$ and the inelastic strain increment vanishes. Otherwise, the inelastic part of the deformation is defined by the flow rule (or normality rule) as:

$\left\{\Delta \varepsilon^{p}\right\}=\Delta \bar{\varepsilon}^{p}\left\{\frac{\partial F}{\partial\{\sigma\}}\right\}=\Delta \bar{\varepsilon}^{p} \frac{[P]\{\sigma\}}{\bar{\sigma}}$

For plastic deformation, the following consistency condition $(d F=0)$ should be satisfied and leads to the increment of the effective plastic strain:

$\Delta \bar{\varepsilon}^{p}=\frac{\left\langle\frac{\partial F}{\partial\{\sigma\}}\right\rangle[C]}{\left\langle\frac{\partial F}{\partial\{\sigma\}}\right\rangle[C]\left\{\frac{\partial F}{\partial\{\sigma\}}\right\}+\frac{\partial \bar{\sigma}}{\partial \bar{\varepsilon}^{p}}}\{\Delta \varepsilon\}$

Substituting (Eq. (14)) and (Eq. (15)) into (Eq. (13)) gives:

$$
\begin{aligned}
& \{\Delta \sigma\}=[C]\left([I]-\frac{\left\{\frac{\partial F}{\partial\{\sigma\}}\right\}\left\langle\frac{\partial F}{\partial\{\sigma]}\right\rangle[C]}{\left\langle\frac{\partial F}{\partial\langle\sigma]}\right\rangle[C]\left\{\frac{\partial F}{\partial\langle\sigma]}\right\}+\frac{\partial \bar{\sigma}}{\partial \bar{\partial} \bar{D}}}\right)\{\Delta \varepsilon\} \\
& =\left[H_{e p}\right]\{\Delta \varepsilon\}
\end{aligned}
$$

where $\left[H_{e p}\right]$ is the material tangent matrix.

Finally, the updated stress vector (Eq.12) should satisfy the second consistency condition $(F=0)$. An algorithm based on a radial returns predictor $[26,27]$ was implemented in order to return the stresses to the yield surface. In fact, for an increment strain $\{\Delta \varepsilon\}$, an initial elastic prediction step $\left\{\Delta \sigma_{E}\right\}$ is carried out. If the yield function is greater than zero an iterative correction procedure uses the normal of the last yield surface is used until that the yield function vanishes.

\section{Formulation aspects and equilibrium relationships}

The DKT12 element is a triangular facet element resulting from the superposition of the CST membrane element and the DKT6 plate element (see Fig. 3). It has twelve DOF (nine translations $(u, v, w)$ at the corner nodes and three rotations $\theta_{s}$ at the mid-side nodes).

The virtual strain is composed of membrane and bending parts:

$\left\{\varepsilon^{*}\right\}=\left\{e^{*}\right\}+z\left\{\chi^{*}\right\}, \quad\left(-\frac{h}{2} \leqslant z \leqslant+\frac{h}{2}\right)$ 


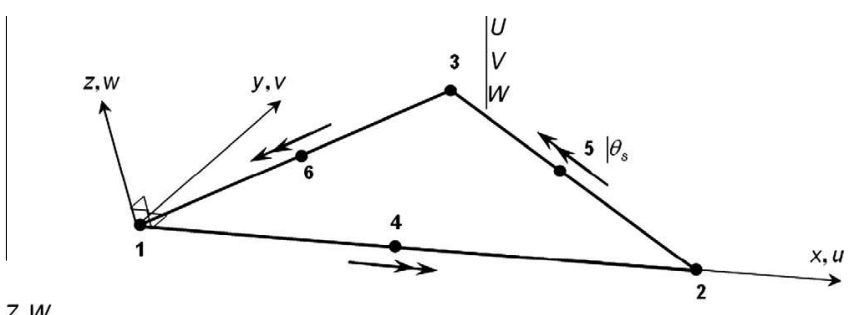

Z,W

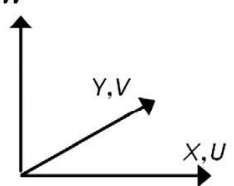

Fig. 3. DKT12 shell element (CST + DKT6).

where the thickness $h$ is assumed to be constant per element.

The virtual membrane strains $\left\{e^{*}\right\}$ on the mean surface are expressed in terms of the virtual displacement components $\left(u^{*}\right.$ and $\left.v^{*}\right)$ of the element:

$\left\{e^{*}\right\}=\left\{\begin{array}{c}u_{x}^{*} \\ v_{y}^{*} \\ u_{y}^{*}+v_{, x}^{*}\end{array}\right\}=\left[B_{m}\right]_{(3 \times 9)}\left\{u_{n}^{*}\right\}$

with $\left\langle u_{n}^{*}\right\rangle=\left\langle\begin{array}{llll}u_{i}^{*} & v_{i}^{*} & w_{i}^{*} & \ldots\end{array}\right\rangle_{(i=1,2,3)}$

The virtual bending strains are expressed in a simple form considering the Discrete Kirchhoff Triangular plate element called DKT6. The DKT6 element has six DOF (three transverse displacements $w$ at the corner nodes and three mid-side rotations $\theta_{s}$ along the element sides:

$\left\{\chi^{*}\right\}=\left[\left[B_{w}\right]\left[B_{\theta}\right]\right]\left\{w_{n}^{*}\right\}=\left[B_{f}\right]_{(3 \times 6)}\left\{w_{n}^{*}\right\}$

with $\left\langle w_{n}^{*}\right\rangle=\left\langle\begin{array}{llllll}w_{1}^{*} & w_{2}^{*} & w_{3}^{*} & \theta_{s 4}^{*} & \theta_{s 5}^{*} & \theta_{s 6}^{*}\end{array}\right.$

The relations (17)-(19) lead to the strain operator of the element with 12 DOF:

$\left\{\varepsilon^{*}\right\}=\left(\left[B_{m}\right]+z\left[B_{f}\right]\right)\left\{u_{n}^{*}\right\}$

with : $\left\langle u_{n}^{*}\right\rangle=\left\langle\begin{array}{lllll}u_{i}^{*} & v_{i}^{*} & w_{i}^{*} & \theta_{3+i}^{*} & \ldots\rangle_{(i=1,2,3)}\end{array}\right.$

The equilibrium of the structure, at the unknown configuration $C^{k}$ (or $C^{i+1}$ at the iteration $i+1$ ), is expressed by the principle of virtual work (PVW) in terms of quantities defined on the last known configuration $C^{i}$ (iteration $i$ ). The PVW is written in function of the second Piola-Kirchhoff (PK2) stress $\{S\}$ and the virtual Green-Lagrange strain $\left\langle E^{*}\right\rangle$ as:

$W=W_{\text {int }}-W_{\text {ext }}=\int\left\langle E^{*}\right\rangle\{S\} d V-\int\left\langle u^{*}\right\rangle\{f\} d V=0$

where $\left\langle u^{*}\right\rangle$ the virtual displacement and $\{f\}$ the external force.

The virtual work of the unknown configuration $C^{k}$ (or $C^{i+1}$ at the iteration $i+1$ ) is linearly approached as follows:

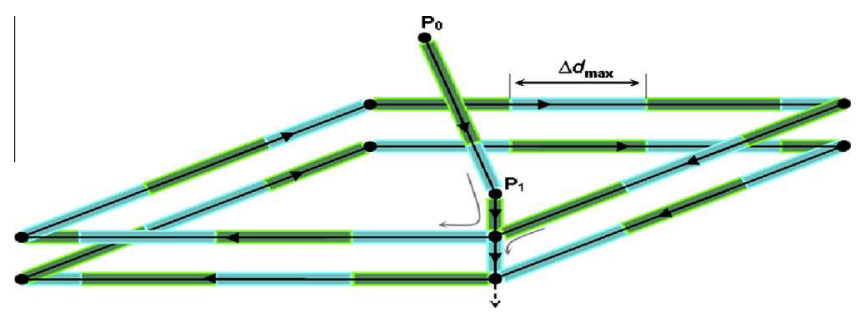

Fig. 5. Subdivision of the tool path (1st step).

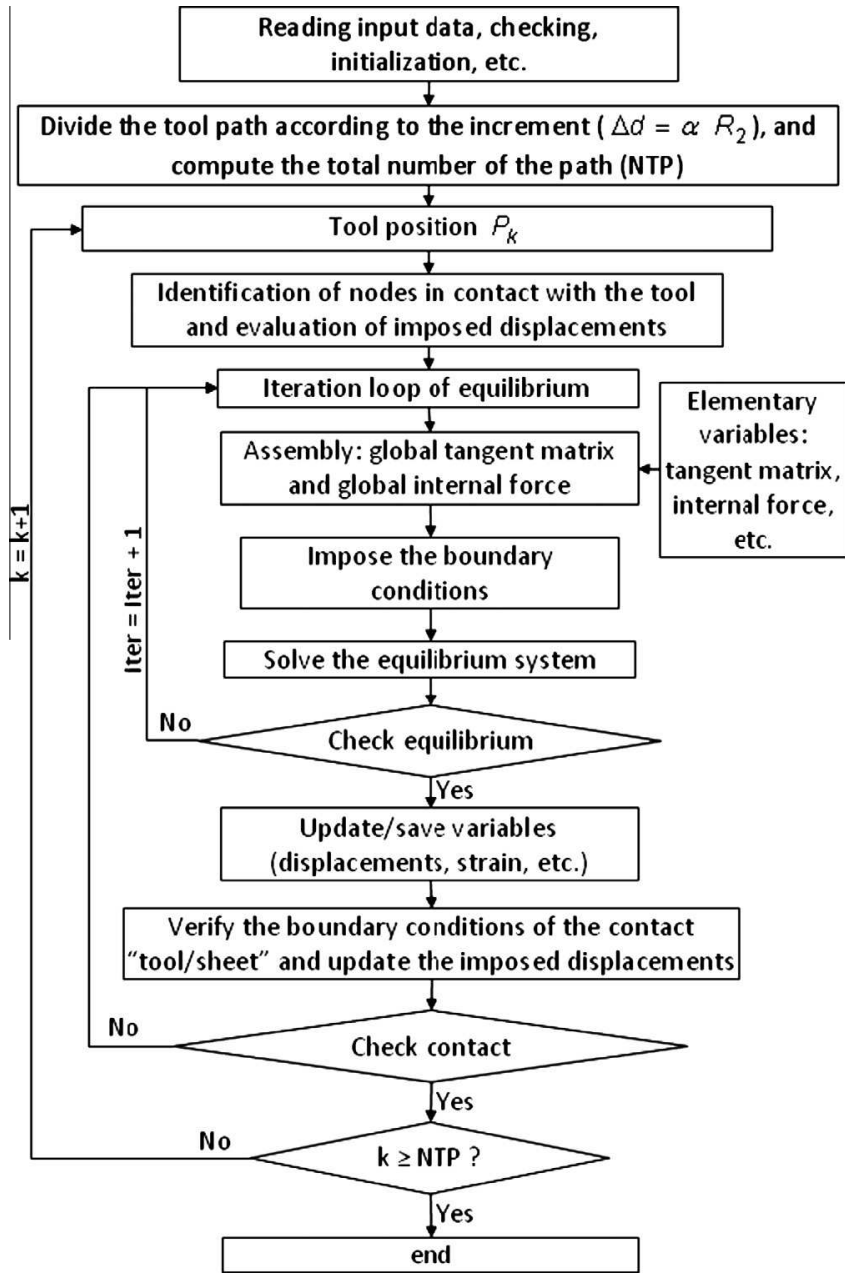

Fig. 6. Flow chart of the ISF-SAM

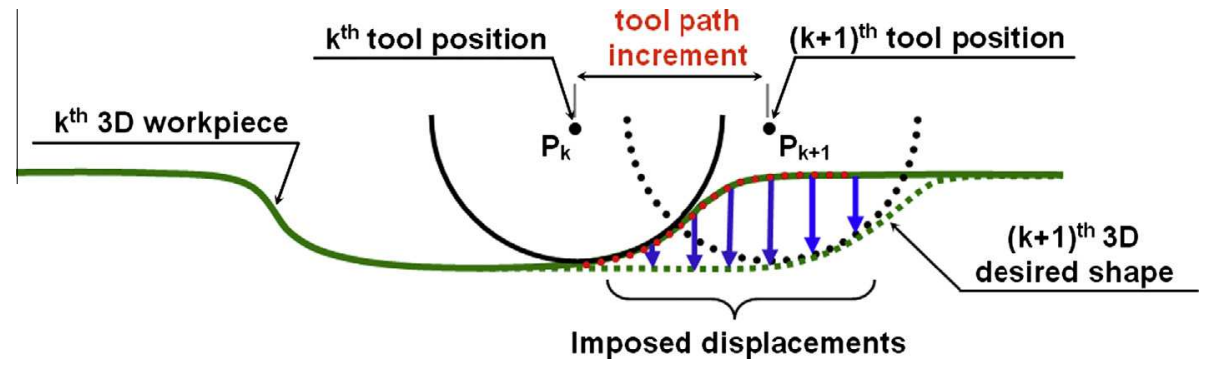

Fig. 4. Principle of the contact management procedure. 


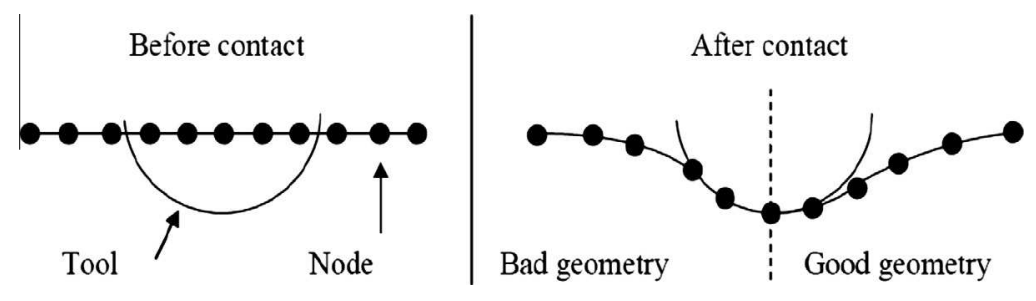

Fig. 7. Incorrect geometry if too many nodes are kept (or forced) in contact with the tool.

$$
\begin{gathered}
\int\left(\left\langle E^{*}\right\rangle\{\Delta S\}+\left\langle\Delta E^{*}\right\rangle\{S\}\right) d V-\int\left\langle u^{*}\right\rangle\{\Delta f\} d V \\
=\int\left\langle u^{*}\right\rangle\{f\} d V-\int\left\langle E^{*}\right\rangle\{S\} d V
\end{gathered}
$$

Since the two successive configurations $\left(\mathrm{C}^{\mathrm{i}}\right.$ and $\left.\mathrm{C}^{\mathrm{i}+1}\right)$ are very close, the PK2 stresses and the virtual Green-Lagrange strains are numerically equivalent to the Cauchy stresses and virtual linear strains, respectively. Thus, the relation (22) can be written as follow:

$$
\begin{aligned}
& \int\left(\left\langle\varepsilon^{*}\right\rangle\{\Delta \sigma\}+\left\langle\Delta E^{*}\right\rangle\{\sigma\}\right) d V-\int\left\langle u^{*}\right\rangle\{\Delta f\} d V \\
& =\int\left\langle u^{*}\right\rangle\{f\} d V-\int\left\langle\varepsilon^{*}\right\rangle\{\sigma\} d V
\end{aligned}
$$

where the Cauchy stresses increment $\{\Delta \sigma\}$ is defined by the elastoplastic constitutive law (see Section $3\{\Delta \sigma\}=\left[H_{e p}\right]\{\Delta \varepsilon\}$ ).

Finally, the relation (23) and the DKT12 formulation lead to the global discrete finite-element system:

$$
\begin{aligned}
& {\left[K_{T}^{i}\right]\{\Delta U\}=\left\{F_{\text {ext }}^{i}\right\}-\left\{F_{\text {int }}^{i}\right\}} \\
& {\left[K_{T}^{i}\right]=\sum_{\text {elements }}[T]^{T}\left(\left[k_{e p}\right]+\left[k_{g}\right]-\left[k_{f}\right]\right)[T]} \\
& {\left[k_{e p}\right]=\int\left(\left[B_{m}\right]^{T}+z\left[B_{f}\right]^{T}\right)\left[H_{e p}\right]\left(\left[B_{m}\right]+z\left[B_{f}\right]\right) d v} \\
& {\left[k_{g}\right]=\int\left\langle\Delta E^{*}\right\rangle\{\sigma\} d v}
\end{aligned}
$$

where $\{\Delta U\}$ is the nodal unknown (displacements and rotations) vector.

$\left\{F_{\text {int }}^{i}\right\}$ and $\left\{F_{\text {ext }}^{i}\right\}$ are the global internal and external force vectors. $\left[K_{T}^{i}\right]$ is the tangent stiffness matrix, $[T]$ is the transformation matrix. $\left[k_{e p}\right],\left[k_{g}\right]$ and $\left[k_{f}\right]$ are the element elasto-plastic stiffness matrix, geometric stiffness matrix and the load following matrix. We note that $\left[k_{g}\right]$ is obtained using only the quadratic part of the

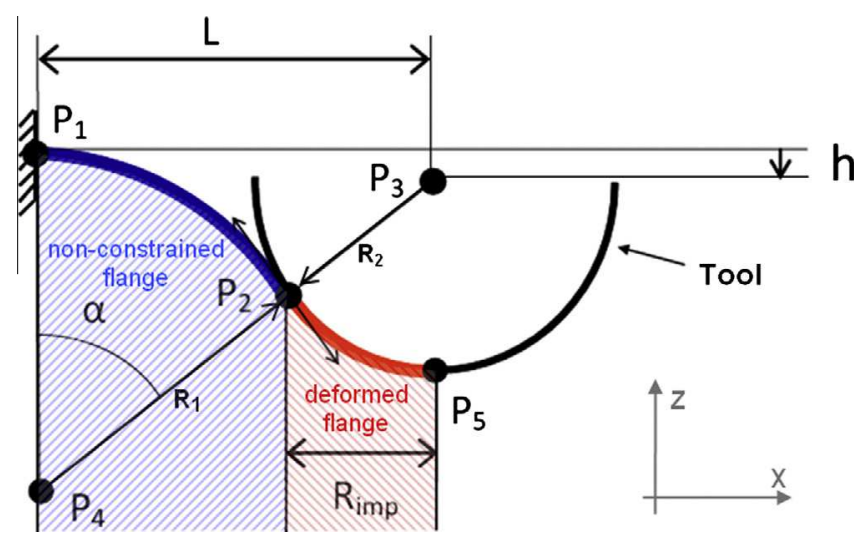

Fig. 8. Contact with the tool and critical radius.
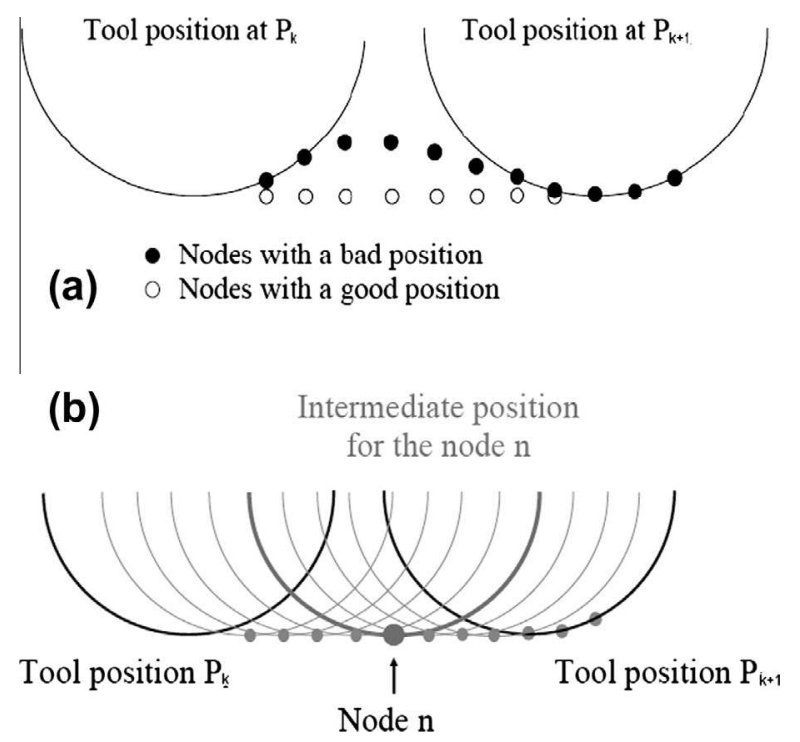

Fig. 9. Tool position strategy.

Green-Lagrange membrane strains which lead to the following expression:

$\int\left\langle\Delta E^{*}\right\rangle\{\sigma\} d v=\int \sum_{k=1}^{3}\left[M_{k}\right]^{T}[\sigma]\left[M_{k}\right] d v$

with:

$\left[M_{1}\right]=\frac{1}{2 A}\left[\begin{array}{llllllllllll}y_{23} & 0 & 0 & 0 & y_{31} & 0 & 0 & 0 & y_{12} & 0 & 0 & 0 \\ x_{32} & 0 & 0 & 0 & x_{31} & 0 & 0 & 0 & x_{21} & 0 & 0 & 0\end{array}\right]$

$\left[M_{2}\right]=\frac{1}{2 A}\left[\begin{array}{llllllllllll}0 & y_{23} & 0 & 0 & 0 & y_{31} & 0 & 0 & 0 & y_{12} & 0 & 0 \\ 0 & x_{32} & 0 & 0 & 0 & x_{31} & 0 & 0 & 0 & x_{21} & 0 & 0\end{array}\right]$

$\left[M_{3}\right]=\frac{1}{2 A}\left[\begin{array}{llllllllllll}0 & 0 & y_{23} & 0 & 0 & 0 & y_{31} & 0 & 0 & 0 & y_{12} & 0 \\ 0 & 0 & x_{32} & 0 & 0 & 0 & x_{31} & 0 & 0 & 0 & x_{21} & 0\end{array}\right]$

$[\sigma]=\left[\begin{array}{cc}\sigma_{x} & \sigma_{x y} \\ \sigma_{y x} & \sigma_{y}\end{array}\right]$

The matrix $\left[k_{f}\right]$ and the external force vector $\left\{F_{\text {ext }}^{i}\right\}$ vanish according to the assumptions introduced via the contact procedure.

\section{Contact assumption and tool path control parameter}

In the ISF process, the contact zone between the tool and the sheet is small and is continually changing with the movement of the tool along its path. Standard contact algorithms, used in commercial finite element codes, give good results but the computational times can be very large. This is due to the nonlinearity of the contact between the sheet and the tool, and also due to the very small tool displacement increments necessary to correctly manage the contact. To correctly model the ISF process in which 
the tool trajectory can be very long and complex, a very large number of tool displacement increments is required. The major simplification introduced in our ISF-SAM approach consists in replacing the tool action by imposed displacements. An algorithm is developed to find the nodes supposed to be in contact with the tool and to estimate their imposed displacements during a tool displacement increment (Fig. 4). This is done by taking into account the geometry of the blank at the beginning of that increment and according to the geometric assumptions.

This algorithm was tested through the commercial code Abaqus and satisfactory results have been obtained by Robert et al. [28]. The goal is to simplify the management of the contact between the tool and the sheet which leads to a reduction of the CPU time. The procedure is composed of three main steps. The first one consists to subdivide the given tool path according to a user parameter called $\alpha$. This parameter controls the size of the displacement increment between two successive positions of the tool along a given direction by defining a maximal value $\Delta d_{\max }$ (Fig. 5):

$\Delta d_{\max }=\alpha \cdot R$

where $R$ is the tool radius.

In the second step geometric assumptions are used to identify the nodes on which displacements will be imposed. For each node identified in contact with the tool, only one DOF (vertical displacement $\mathrm{W}$ ) is computed and imposed. The mid-side nodes and their DOF are not concerned by the identification procedure. The DOFs $U$ and $V$ will be predicted through the resolution of the global discrete finite-element system (relation 24) which described the equilibrium of the structure. This choice avoids to force nodes to be in contact with the tool and to lock locally the sheet, which could lead to impose the strains of some elements in the tool vicinity.

The third step is performed after the resolution of the equilibrium system and consists to verify if there are one or several nodes which were forgotten and were not identified in the second step. If it is true, we move to the next increment. On the other hand, the boundary conditions must be updated and an intermediate equilibrium step of the structure must be carried out and then we pass to the next increment. The flow chart of the ISF-SAM is shown in Fig. 6.

The second step is performed through two complementary methods which are described in sections (4.1 and 4): At each increment and for each node a critical radius (Section 4.1) is computed according to an intermediate tool position (Section 4.2). These methods allow us to use a tool displacement increment as large as possible, and to find the needed displacement " $W$ " to impose.

\subsection{Nodes in the contact}

The interpenetration between both surfaces (tool and sheet) for a given tool position, is not sufficient to determine nodes in the contact zone, particularly when the tool displacement increment is large. In fact, if too many nodes are kept (or forced) in contact with the tool surface at the end of the increment, the geometry of the deformed flange is not correct (see Fig. 7). Only some nodes in the interpenetration zone must be considered to be in contact with the tool surface.

A criterion based on a geometrical assumption has been developed to obtain a more realistic deformed shape. A critical radius is computed in order to limit the contact zone and used to consider (or not) that the node is in contact with the tool. For that two circular arcs are used to define the assumed deformed flange (see Fig. 8). The first arc $C_{1}$, of center $P_{4}$ and of radius $R_{1}$, passes through $P_{1}$ and $P_{2}$ and it represents the non-constrained surface of the flange. The second arc $C_{2}$, joining $P_{2}$ and $P_{5}$, represents the contact zone with the tool (it has a radius $R_{2}$ and a center $P_{3}$ ). The point $P_{1}$ is sufficiently far from the contact zone and the blank is considered to be fixed. The two arcs are assumed to be tangential at the point of intersection $\mathrm{P}_{2}$.

The angle $\alpha$ is defined as the angle between the line $\mathrm{P}_{4} \mathrm{P}_{3}$ and the $Z$ axis (or $\mathrm{P}_{4} \mathrm{P}_{1}$ ). Therefore, the distance $L$ and the algebraic value $h$ are defined as follows:

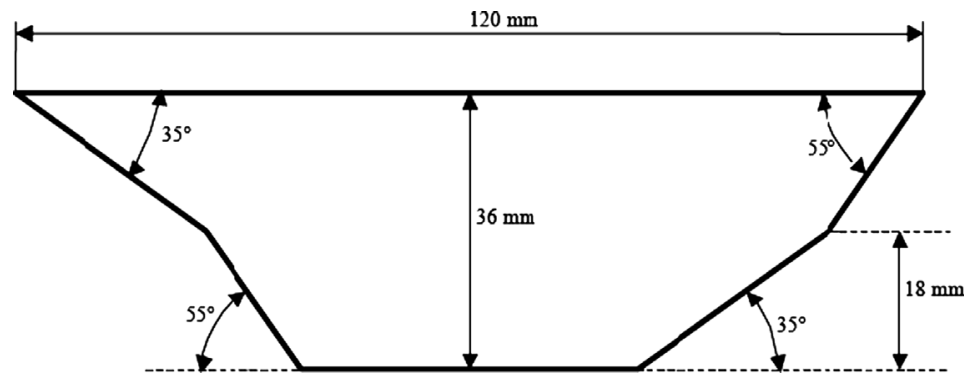

(a)

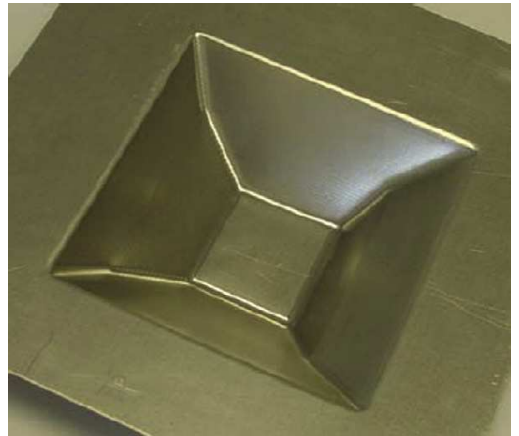

(b)

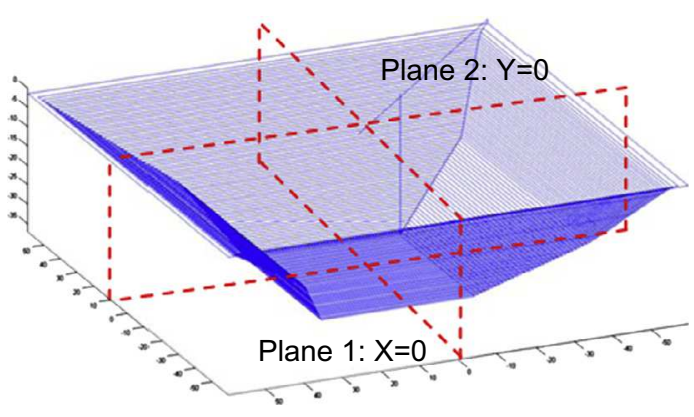

(c)

Fig. 10. Geometrical parameters. 
$h=\overrightarrow{P_{1} P_{3}} \cdot \vec{Z}$ and $L=\left|\overrightarrow{P_{1} P_{3}} \cdot \vec{X}\right|$

The contact zone between the tool and the sheet is defined through the projection of the line $\mathrm{P}_{2} \mathrm{P}_{5}$ on the $X$ axis. This distance is referred as $R_{\text {imp }}$ (see Fig. 8) which is computed as follow:

$R_{i m p}=R_{2} \sin (\alpha)$
The angle $\alpha$ could be computed using the following relationships:

$\left\{\begin{array}{l}R_{1}=\frac{\left(R_{2}+h\right)^{2}-L^{2}}{2\left(R_{2}+h\right)} \\ \alpha=\tan ^{-1}\left(\frac{L}{R_{1}+h}\right)\end{array}\right.$

This distance $L$ is limited to 5 times the tool radius $R_{2}$. This value has been chosen based on our house experience.

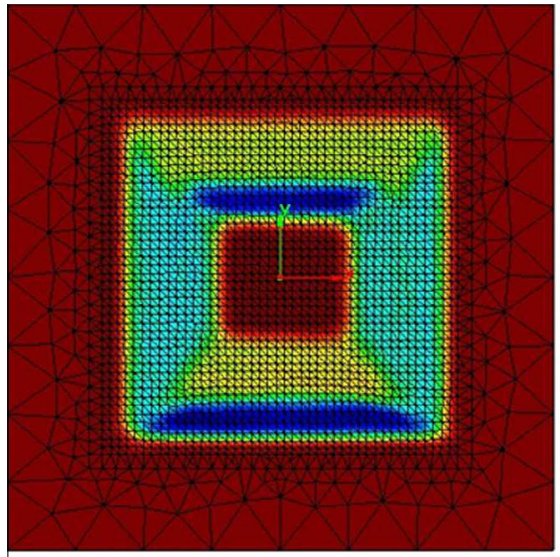

(a) $\Delta d=0.5 R$

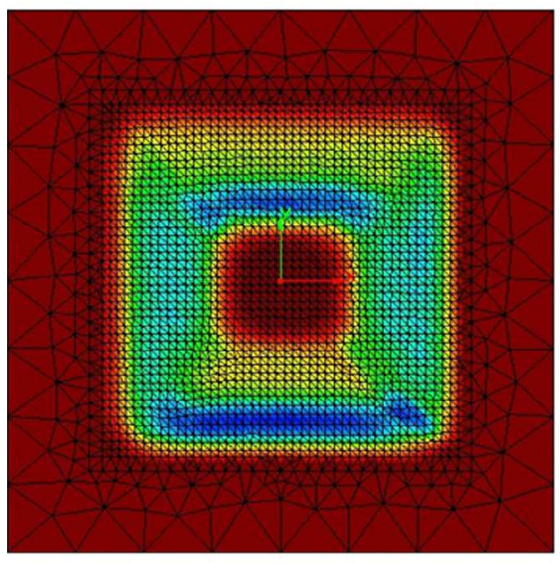

(c) $\Delta d=2 R$

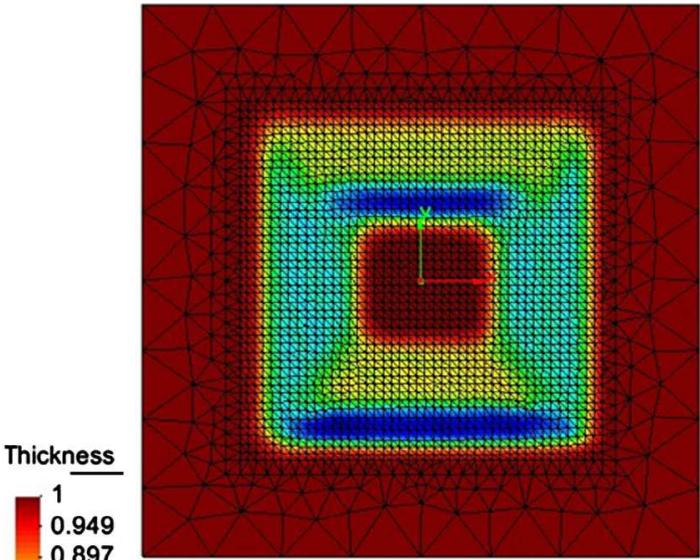

(b) $\Delta d^{\prime}=1 R$
0.795

0.744

0.692

0.641

0.59

0.538

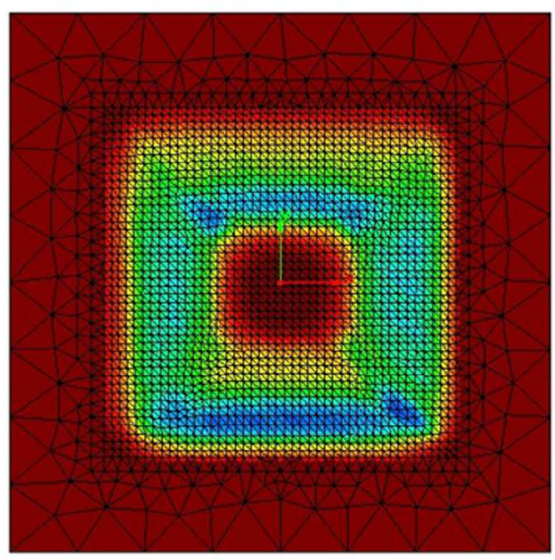

(d) $\Delta d=3 R$

Fig. 11. Thickness distributions.

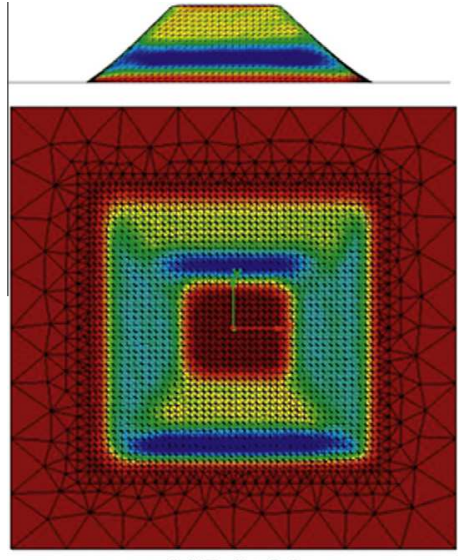

(a) ISF-SAM

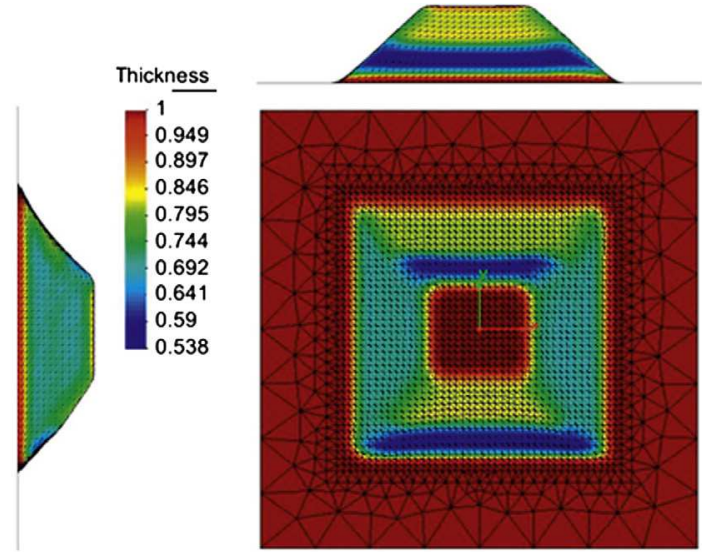

(b) Abaqus

Fig. 12. Thickness distribution using ISF-SAM (a) and Abaqus (b) 


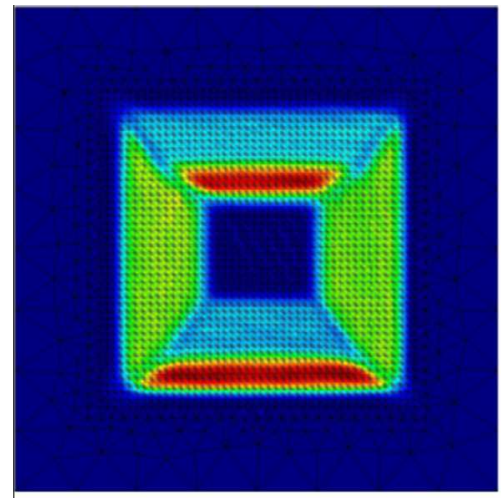

(a) ISF-SAM (0.5R)
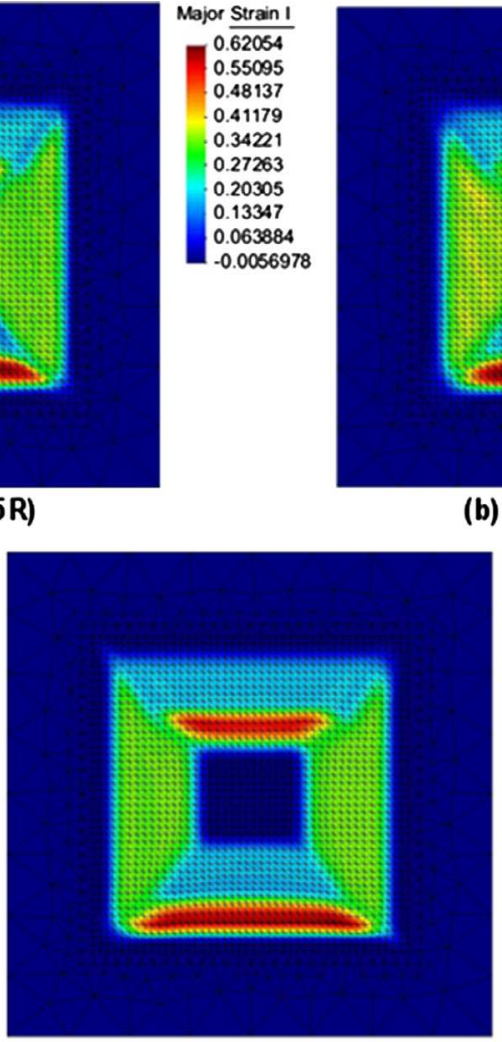

(c) Abaqus

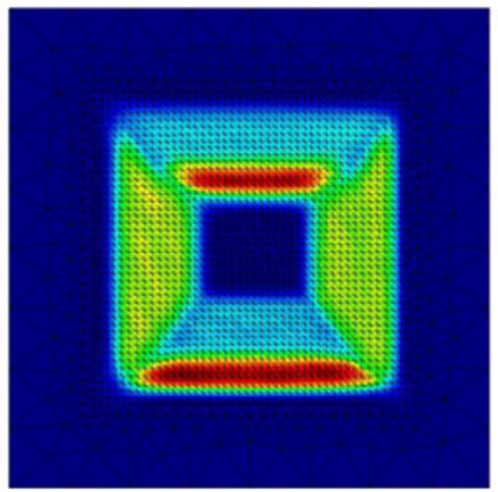

(b) ISF-SAM (1R)

Major Strain I

0.059526

$-0.006803$

Major Strain I

0.6198

0.55067

0.48153

0.34327
0.27413

0.205

0.13587

0.066733

$-0.0023997$

Fig. 13. Major strains distributions in lower surface using ISF-SAM (a, b) and Abaqus (c)

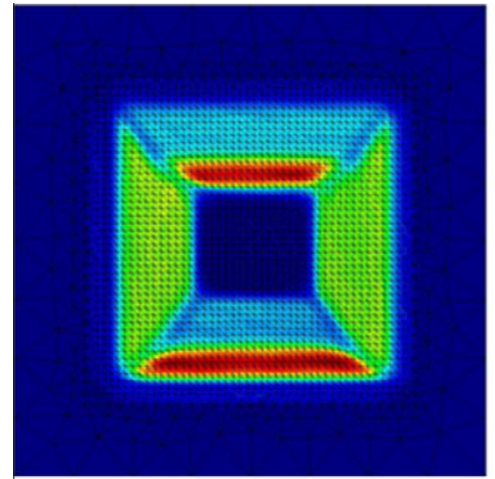

(a) ISF-SAM (0.5R)

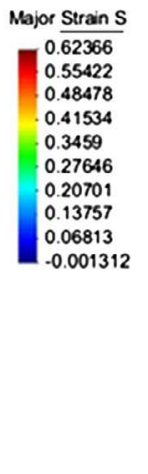

0.62366
0.55422
0.48478
0.41534
0.3459
0.27646
0.20701
0.13757
0.06813
-0.001312

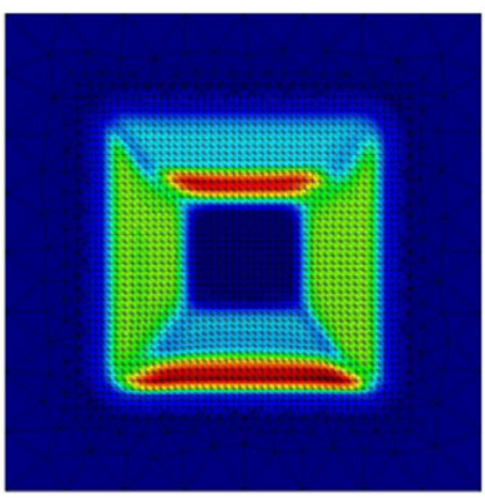

(c) Abaqus

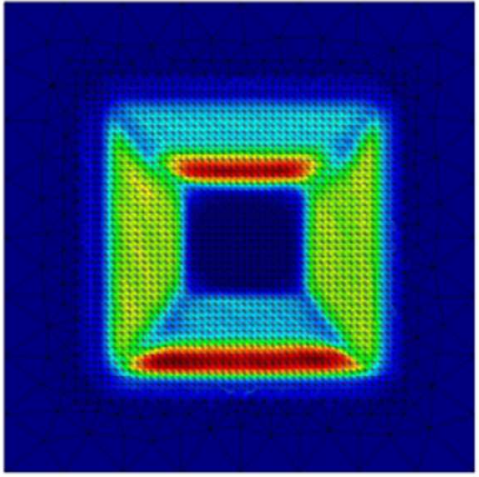

(b) ISF-SAM (1R)

$$
\begin{gathered}
\text { Major Strain S } \\
0.62171 \\
0.55263 \\
0.48355 \\
0.41447 \\
0.34539 \\
0.27631 \\
0.20724 \\
0.13816 \\
0.069078 \\
.3 .9968 \mathrm{e}-16
\end{gathered}
$$

0.19675

0.13102

0.065284

$-0.00045068$

Fig. 14. Major strains distributions in upper surface using ISF-SAM (a, b) and Abaqus (c). 


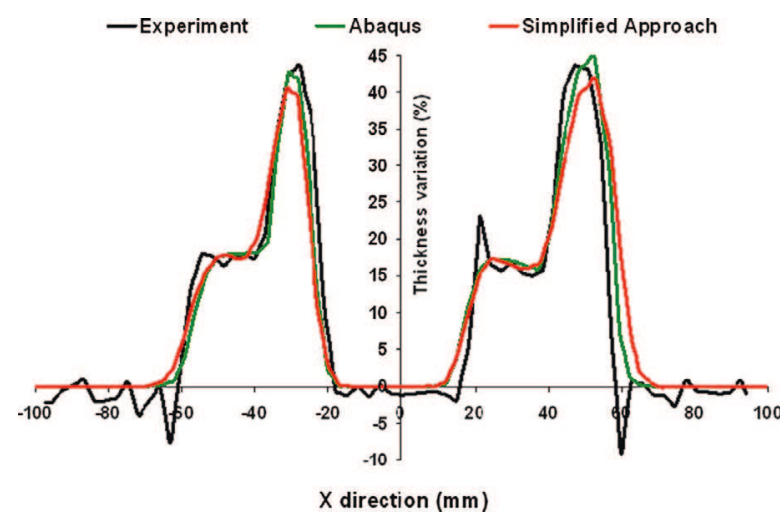

(a) Thickness variation in the cut plane $Y=0$

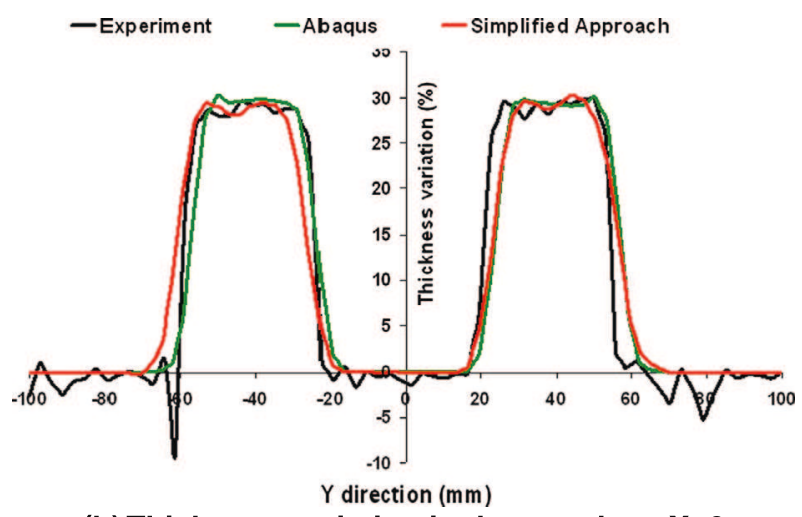

(b) Thickness variation in the cut plane $X=0$

Fig. 15. Thickness variation.

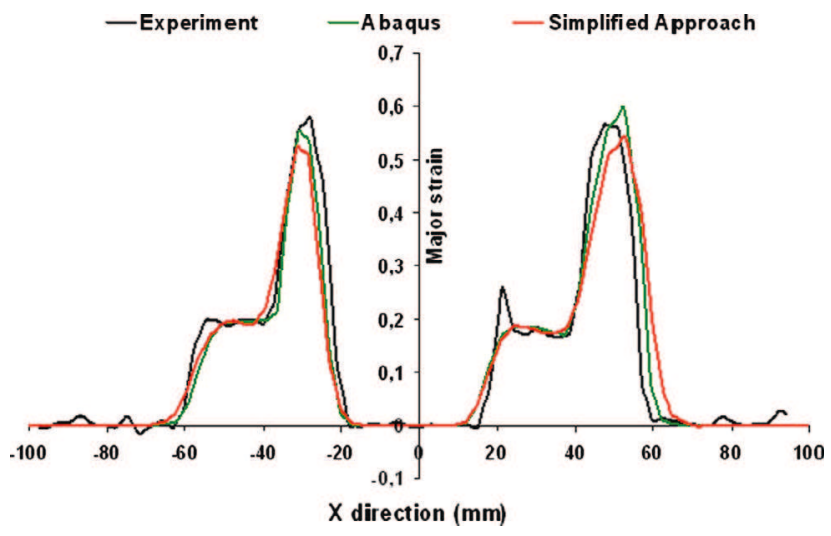

(a) Major strain variation in the cut plane $Y=0$

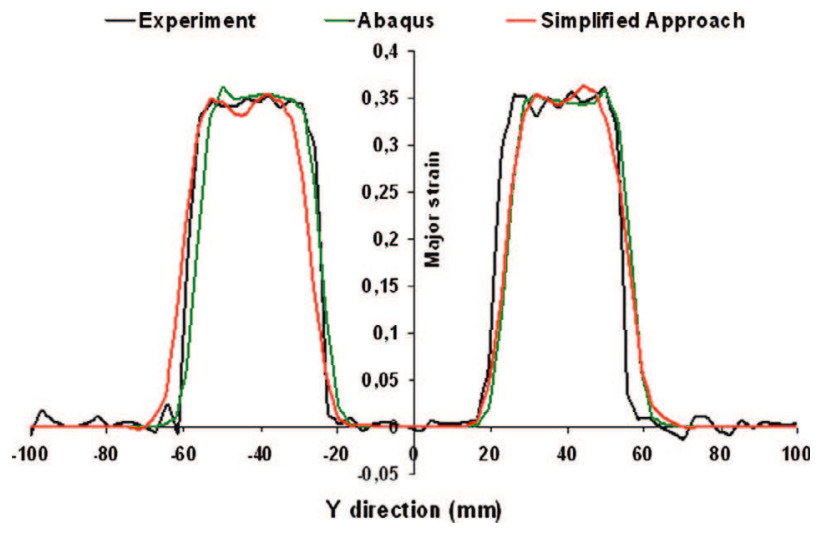

(b) Major strain variation in the cut plane $X=0$

Fig. 16. Major strain variation.

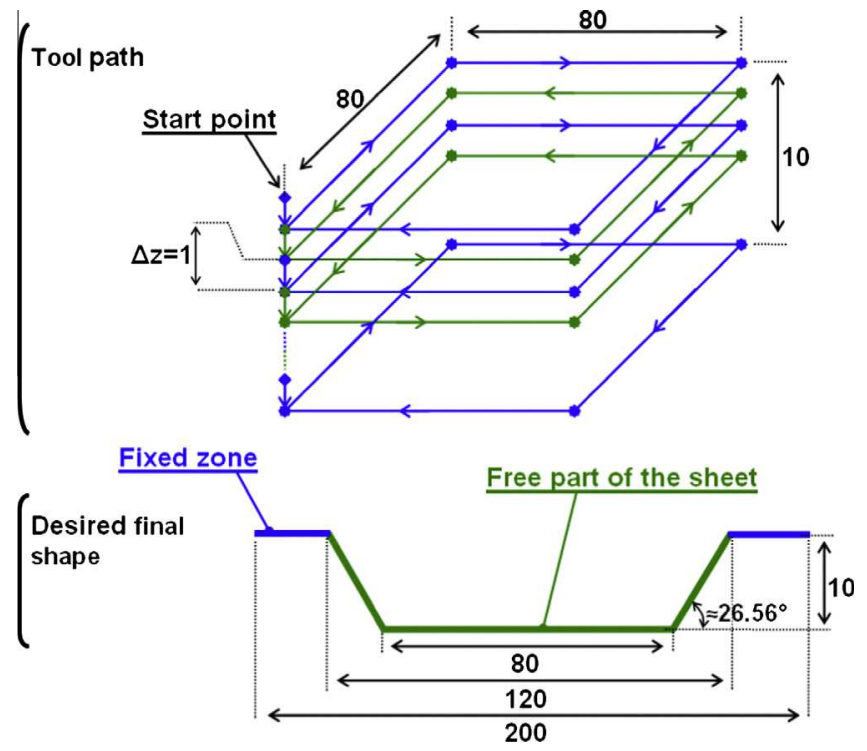

Fig. 17. Tool path and geometry of the final shape ( $\mathrm{mm})$.

\subsection{Intermediate position of the tool}

To allow a tool displacement increment as large as possible, it is necessary to position the tool judiciously. Let us define $P_{k}$ and $P_{k+1}$ as two different tool positions at the beginning and the end of an increment, respectively. For a node between both tool positions, it is incorrect to use this algorithm with the tool in the $P_{k+1}$ position. In fact, some intermediate nodes will (or will not) have an imposed displacement as shown in Fig. 9-a.

To avoid this issue it is possible to use small tool increments however this involves a long computation time. An alternative solution has been proposed, which consist to find an intermediate position of the tool between $P_{k}$ and $P_{k+1}$ for each node. This position minimizes the distance between the tool center and the node as shown in Fig. 9-b. Then, the imposed displacement will be estimated if the node is considered in the contact zone which is limited by the critical radius (Section 4.1).

\section{Results and discussion}

In this section, two applications of ISF were investigated and the results carried out with the ISF-SAM code were compared to numerical and experimental results.

\subsection{Pyramidal part}

The first benchmark is a pyramidal part (see Fig. 10) [16]. Two of the opposing walls have different inclinations. One wall has a changeover from a steep angle $\left(55^{\circ}\right)$ to a shallow angle $\left(35^{\circ}\right)$. The other wall has an inverse changeover (from shallow angle to steep angle). The remaining two walls have same angle $\left(45^{\circ}\right)$. The frustum of pyramid has a depth of $36 \mathrm{~mm}$ and a base area of 
$120 \times 120 \mathrm{~mm}$. The bottom area is $43.4 \times 43.4 \mathrm{~mm}$. Fig. $8 \mathrm{c}$ shows the trajectory of the tool and two cutting planes on which experimental results are provided.

The initial dimension of the sheet is $200 \times 200 \times 1 \mathrm{~mm}$, the tool has a diameter of $10 \mathrm{~mm}$. The tool path follows the CAD surface at a constant depth, followed by an increase in depth of $0.5 \mathrm{~mm}$. The starting point is at an exterior edge. The material is an aluminium alloy (AA1050). The isotropic hardening behaviour is modelled by the Swift law:

$\sigma_{y}=119.5\left(0.000142+\bar{\varepsilon}^{p}\right)^{0.235}$

The material AA1050 has a Poisson's ratio of 0.33 and a Young's modulus of 70,000 MPa. The Lankford coefficients are: $r_{0}=0.51$, $r_{45}=0.75$ and $r_{90}=0.48$.

A static FE code (Abaqus/standard) has been successfully used to simulate the ISF process, as it is very suitable for highly non-linear problems. In the FE model, the tools are assumed as rigid bodies and the sheet has been meshed with 4394 triangular shell elements called S3R and considering five integration points through the thickness. The same discretization of the sheet has been used to carry out the analysis with the ISF-SAM, and the sheet part under the die has been assumed to be fixed.

Four tool path increments were tested: $\Delta d_{\alpha}=\alpha^{*} R(\alpha=0.5,1,2$, $3)$. A stabilization of results in term of thickness distribution has been observed when the tool path increment value is smaller than one time the tool radius $R$ (Fig. $11 \mathrm{a}-\mathrm{d}$ ).

The sheet thickness prediction obtained using ISF-SAM with a tool path increment of $1 \mathrm{R}$ is compared to the Abaqus result and a good agreement is shown in Fig. 12a and b. The results are given in the same scale using Gid Postprocess interface developed by the International Center for Numerical Methods in Engineering (CIMNE) [29].
To quantify the bending phenomenon, numerical results obtained with ISF-SAM code on lower and upper surfaces have been compared to these of Abaqus. Fig. 13a and b shown that the major strain distributions obtained on lower surface with ISF-SAM are in good agreement with these of Abaqus (Fig. 13c), despite that the maximum values are slightly different when a tool path increment of $1 R$ is used. However, the ISF-SAM results obtained with a tool path increment of $0.5 R$ are very close to Abaqus results. The maximum values are: $0.6198,0.62054$ and 0.59016 for Abaqus, ISFSAM with $\Delta d^{1}=0.5 R$ and ISF-SAM with $\Delta d^{2}=1 R$ respectively. This result shows that the ISF-SAM code covers sufficiently the bending phenomenon and that the error is reasonably acceptable. However, the parameter, called $\alpha$, which control the displacement increment has a significant role. In fact, the accuracy of the FE modelling can be increased by considering a small value of the tool path increment, but this leads to very expensive analysis in term of CPU time. In addition, the increment is also in function of the tool radius. To correctly manage the contact (tool/sheet) under Abaqus (or ISFSAM), the mesh size of the sheet must be less than $1 / 2,1 / 3$, (or $1 / 4$ ) of tool radius. Thus, if the tool radius decreases, the mesh size decreases, and consequently the CPU time increases. With the ISFSAM, the parameter $\alpha$ is given by the user and the increment does not depend of the mesh size. If the tool radius decreases for the same application, the parameter $\alpha$ could be increased in order to keep the same increment, and consequently the CPU time will be improved compared to Abaqus, but the quality of the ISF-SAM results could be degraded.

The analysis performed using the ISF-SAM with the increments, $\Delta d^{1}$ and $\Delta d^{2}$, were carried out in $23 \mathrm{~h} 38 \mathrm{~min}$ and $50 \mathrm{~h} 7 \mathrm{~min}$ of CPU times respectively on an Intel Xeon workstation and in 63h50min using the Abaqus/static finite element code.

On the upper surface (Fig. 14), the major strain distributions obtained using ISF-SAM and Abaqus were compared and again show

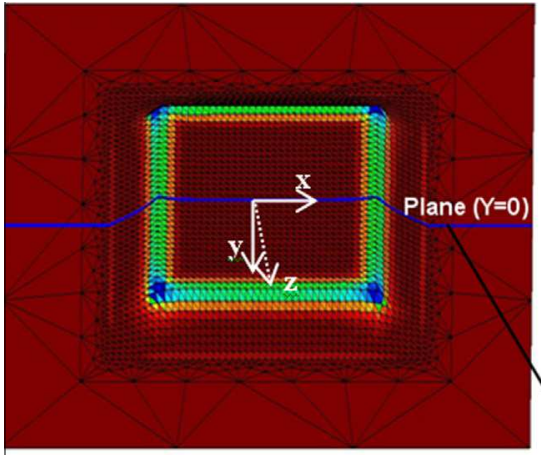

(a) ISF-SAM (0.5R)

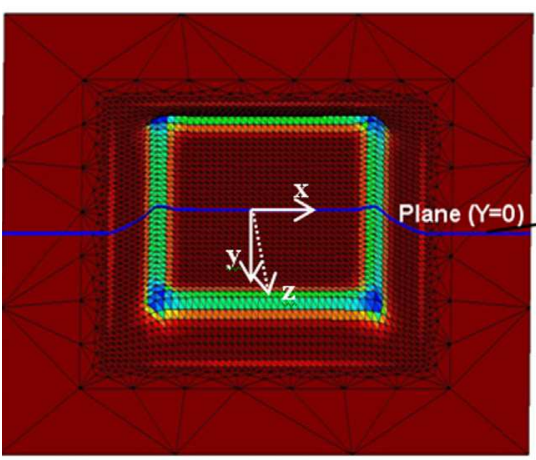

(c) Abaqus

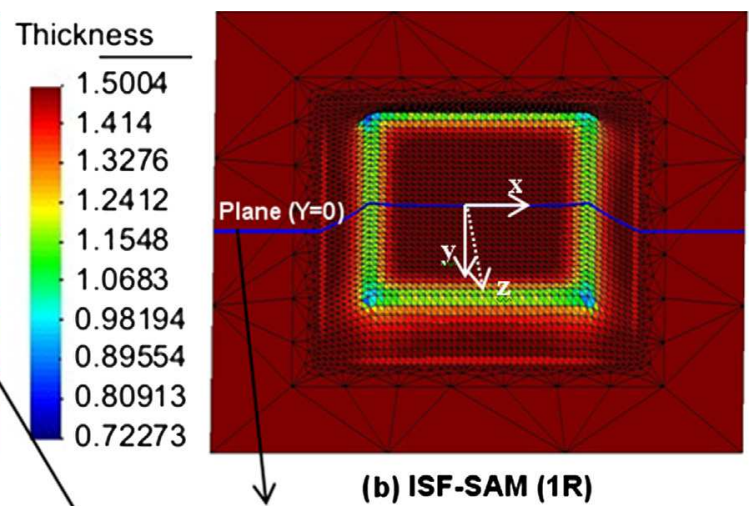

(b) ISF-SAM (1R)

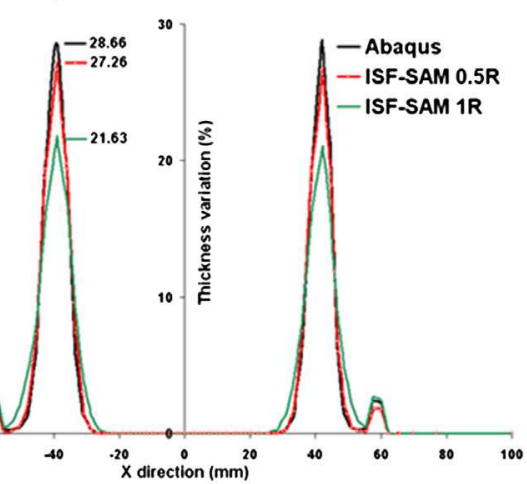

(d) Thickness variation in cut plane $Y=0$

Fig. 18. Thickness distributions. 
that the ISF-SAM code, takes into account the bending phenomenon. According to the results obtained in lower and upper surfaces, it has been concluded that the bending phenomenon for this example is not significant. Thus, a second application was proposed to investigate this phenomenon, which is presented in Section 5.2.

Numerical predictions carried out using ISF-SAM and Abaqus are compared to experimental results and shown in Figs. 15 and 16. The thickness variations along the $X=0$ and $Y=0$ cut, presented in Fig. 15 shows a good correlation between numerical and experimental results. Also, the same conclusion regarding the major strain variations presented in Fig. 16. Finally, the numerical results obtained with the ISF-SAM code, the comparison with these of Abaqus and the experimental validation confirms the potentiality of the present FEM analyses.
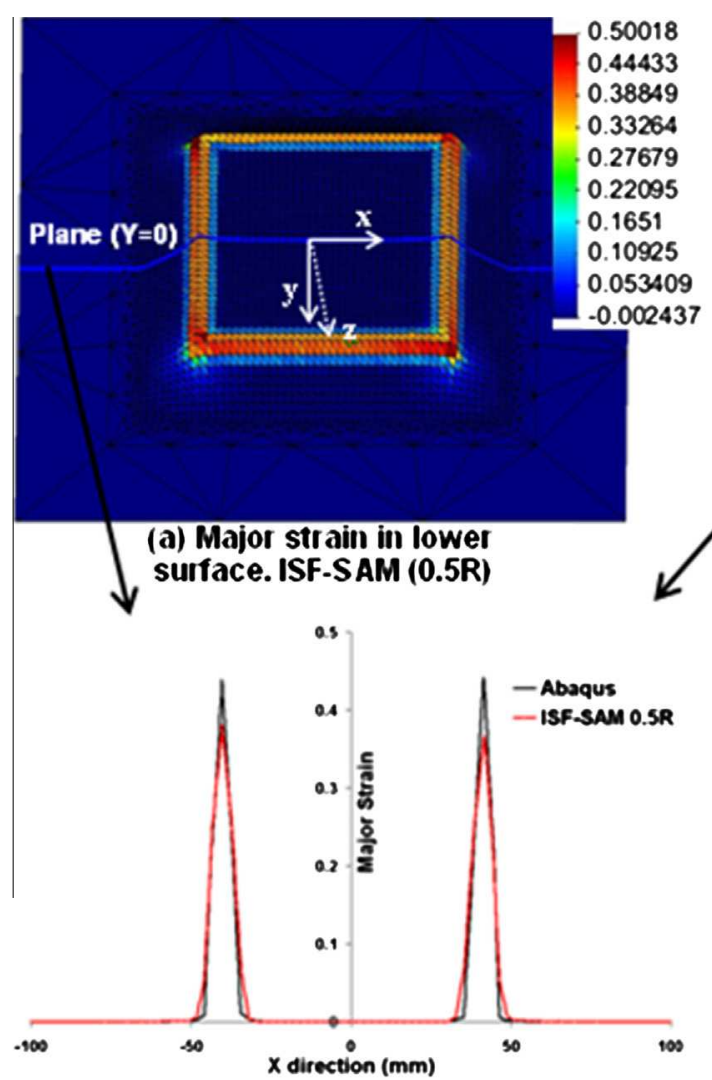

(c) Major strain in lower surface obtained along the cit plane $Y=0$

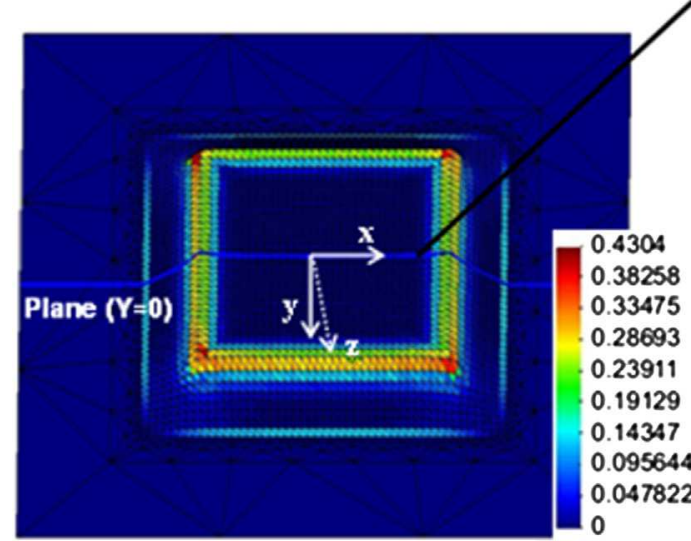

(e) Major strain in upper surface. ISF-SAM $(0.5 R)$

\subsection{Square box}

A second application, called square box, has been proposed in order to investigate the bending phenomenon and to illustrate the capabilities of the ISF-SAM to take into account this phenomenon. The material parameters of the sheet and the tool diameter are the same as those used for the pyramidal benchmark. The initial dimensions of the sheet are $200 \times 200 \times 1.5 \mathrm{~mm}$. The frustum of the square box has a depth of $10 \mathrm{~mm}$ and a base area of $80 \times 80 \mathrm{~mm}$. The tool path and the dimensions of the desired shape are shown in Fig. 17.

The sheet is meshed using 5422 triangular elements (DKT12 for ISF-SAM and S3R for Abaqus) with five integration points through the thickness. The sheet thickness distributions obtained using

Fig. 19. Major strain variations obtained in lower and upper surfaces. 
ISF-SAM with increments of $\Delta d=0.5 R$ and $\Delta d=1 R$ (Fig. 18a and b) are compared to the Abaqus result (Fig. 18c) and a best agreement of results was observed for an increment of $\Delta d=0.5 R$. An excessive thinning of $51.5 \%$ was obtained at the end using Abaqus code. The same value was obtained for ISF-SAM with $\Delta d=0.5 R$ and an excessive thinning of $50.3 \%$ with $\Delta d=1 R$. The thickness variations obtained along the line defined by the cut plane $(Y=0)$, which are reported in Fig. 18d, show that the displacement increment of $0.5 R$ allows more accuracy result for ISF-SAM. In fact, significant gaps are observed in the vicinity of $\pm 40 \mathrm{~mm}$ when a displacement increment of $\Delta d=1 R$ is used.

In Fig. 19 are compared the major strain distributions obtained by Abaqus and ISF-SAM with an increment of $\Delta d=0.5 R$. Fig. 19a and $b$ show the distributions obtained on the lower surfaces. It could be noted that the distributions are not symmetric and significant deformations are located principally along the contour of the square box base. Despite the gap between the maximum values a good agreement of the results is observed. Fig. 19c compares the evolution of the major strains along the line defined by the cut plane $(Y=0)$ where the maximum values are 0.38 and 0.43 for ISF-SAM and Abaqus respectively.

The major strains distributions obtained on the upper surfaces are reported in Fig. 19e and $\mathrm{f}$ and they again confirm that the ISF-SAM approach provides results in good agreement with Abaqus. Significant deformations have been again located along the contour of the square box base but it should be noted that there are also minor deformations on the borders near to the clamped shape. Fig. 19d presents the evolution of the major strains along the line defined by the cut plane $(Y=0)$ and shows that the solicitations obtained on the upper surface of the sheet are slightly different than these observed on the lower surface, and within the both cases the solutions of ISF-SAM tend toward these of Abaqus.

Finally, the CPU time was reduced by more than $50 \%$ for this application. The analysis performed using the ISF-SAM with $\Delta d=0.5 R$ was carried out in $13 \mathrm{~h} 24 \mathrm{~min}$ of CPU times on an Intel Xeon workstation and in $30 \mathrm{~h} 50 \mathrm{~min}$ using Abaqus code.

\section{Conclusion}

A simplified numerical approach called ISF-SAM has been developed to simulate the ISF process. A shell element DKT12 was implemented and coupled with an elasto-plastic model based on a classical flow rule. A procedure to manage the tool/sheet contact conditions in the context of the ISF process simulation has been presented. A reduction of CPU time about approximately $63 \%$ has been obtained and at the same time good simulation results are achieved and compared to experimental results. A square box test including more significant bending effect is investigated and shows again the potentiality of the ISF-SAM. Also, we intend to replace the DKT12 element by a rotation free triangular shell element, again with hope to reduction the simulation times. Furthermore, optional parameters will be added to the current ISFSAM in order to expand the application field and to study others benchmark tests of the incremental sheet forming process such as: ISF with double points and/or including a combination of multi-stage forming.

\section{References}

[1] Jackson KP, Allwood JM, Landert M. Incremental forming of sandwich panels. J Mater Process Technol 2008;204:290-303.
[2] Emmens WC, Sebastiani G, van den Boogaard AH. The technology of Incremental Sheet Forming-a brief review of the history. J Mater Process Technol 2010;210:981-97.

[3] Jeswiet J, Micari F, Hirt G, Bramley A, Duflou J, Allwood J. Asymmetric single point incremental forming of sheet metal. CIRP Ann - Manuf Technol 2005;54(2):88-114.

[4] Ambrogio G, De Napoli L, Filice L, Gagliardi F, Muzzupappa M. Application of Incremental Forming process for high customised medical product manufacturing. J Mater Process Technol 2005;162-163:156-62.

[5] Kim YH, Park JJ. Effect of process parameters on formability in incremental forming of sheet metal. J Mater Process Technol 2002;130-131:42-6.

[6] Allwood JM, Shouler DR, Tekkaya AE. The increased forming limits of incremental sheet forming processes. Key Eng Mater 2007;344:621-8.

[7] Eyckens P, Belkassem B, Henrard C, Gu J, Sol H, Habraken AM, et al. Strain evolution in the single point incremental forming process: digital image correlation measurement and finite element prediction. Int J Mater Form 2010:55-71.

[8] Guzmán CF, Gu J, Duflou J, Vanhove H, Flores P, Habraken AM. Study of the geometrical inaccuracy on a SPIF two-slope pyramid by finite element simulations. Int J Solids Struct 2012;49:3594-604.

[9] Micari F, Ambrogiob G, Filice L. Shape and dimensional accuracy in Single Point Incremental Forming: state of the art and future trends. J Mater Process Technol 2007;191:390-5.

[10] Azaouzi M, Lebaal N. Tool path optimization for single point incremental sheet forming using response surface method. Simul Model Pract Theory 2012:24:49-58.

[11] Rauch M, Hascoet JY, Hamann JC, Plenel Yannick. Tool path programming optimization for incremental sheet forming applications. Comput Aided Des 2009;41:877-85.

[12] Hirt G, Ames J, Bambach M, Kopp R. Forming strategies and process modelling for CNC incremental sheet forming. CIRP Ann - Manuf Technol 2004;53(1):203-6.

[13] Duflou JR, Verbert J, Belkassem B, Gu J, Sol H, Henrard C, et al. Process window enhancement for single point incremental forming through multi-step toolpaths. Ann CIRP-Manuf Technol 2008;57(1):253-6.

[14] Bambach M, Taleb Araghi B, Hirt G. Strategies to improve the geometric accuracy in asymmetric single point incremental forming. Prod Eng Res Dev 2009;3:145-56.

[15] Robert C. Contribution to the numerical simulation of sheet metal forming process - application to incremental sheet forming and superplastic forming. $\mathrm{PhD}$ thesis from the Ecole Nationale Supérieur d'Arts et Métiers; 2009.

[16] Henrard C. Numerical simulations of the single point incremental forming process. Ph.D thesis, Université de Liège; 2008.

[17] Lequesne C, Henrard C, Bouffioux C, Duflou J, Habraken AM. Adaptive remeshing for incremental forming simulation. In: NUMISHEET, Interlaken, Switzerland; 2008.

[18] Hadoush A, van den Boogaard A. Substructuring in the implicit simulation of single point incremental sheet forming. Int J Mater Form 2009;2(3):181-9.

[19] Bambach M. A geometrical model of the kinematics of incremental sheet forming for the prediction of membrane strains and sheet thickness. J Mater Process Technol 2010;210:1562-73.

[20] Robert C, Ben Ayed L, Delameziere A, Dal Santo P, Batoz J-L. Development of a simplified approach of contact for incremental sheet forming. Int J Mater Form 2010;3(S1):987-90.

[21] Robert C, Delameziere A, Dal Santo P, Batoz J-L. Comparison between incremental deformation theory and flow rule to simulate sheet-metal forming processes.

[22] Flexform. FP6 Collective research. Development of a flexible manufacturing process for the low series production of metal parts for custom and special vehicles. Deliverable 2.1 (main algorithms), D2.2 (user friendly interface) and D2.3 (quality tests software). European project 3 years; 2006.

[23] Yu Y, Delameziere A, Nouari M, Batoz JL. Towards a simplified approach to simulate the ISF process. In: ICTP 2011 proceedings sheet metal forming; 2011.

[24] Batoz JL, Dhatt G. Modélisation des structures par éléments finis, vol. 3. Paris: Coques, Ed. Hermès; 1992.

[25] Batoz JL, Guo YQ, Shakourzadeh H. Analyse non linéaire de coques minces élasto-plastiques avec l'élément DKT12. Revue Européenne des Eléments Finis 1998;7(1-3):223-39.

[26] Crisfield MA. Non-linear finite element analysis of solids and structures, vol. 1. John Wiley \& Sons Ltd.; 1991.

[27] Ortiz M, Simo JC. An analysis of a new class of integration algorithms for elastoplastic constitutive relations. Int J Numer Meth Eng 1986:23:353-66.

[28] Robert C, Ben Ayed L, Delamézière A, Dal Santo P, Batoz JL. On a simplified model for the tool and the sheet contact conditions for the SPIF process simulation. Key Eng Mater 2009;410-411:373-9.

[29] www.gidhome.com 